\title{
3D-QSARs of Herbicidal 2- $N$-Phenylisoindolin-1-one Analogues as a New Class of Potent Inhibitors of Protox
}

\author{
Min-Gyu Soung, Yoon-Jung Lee, and Nack-Do Sung- \\ Division of Applied Biologies and Chemistru, College of Agriculture and Life Science, \\ Chungham National Cniversit, Daejeon 305-784. Korea. E-mail: ndsung150hammail.net \\ Received December 3, 2008, Accepted Jantuary 28, 2009
}

\begin{abstract}
3D-QSARs for the inhibition activities against protox by herbicidal 2-N-phenylisoindolin-1-one derivatives were studied quantitatively using CoMFA and CoMSIA methods. The result of the statistical quality of optimized

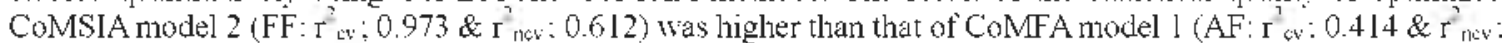
$0.909)$. Also, the relative contribution of the optimized CoMSIA model 2 showed the steric (24.6\%), electrostatic (31.0\%), hydrophobic $(\mathrm{Clog} P, 23.4 \%)$ and $\mathrm{H}$-bond acceptor field $(21.0 \%)$, respectively. From the results of the contour maps, the protox inhibition activities are expected to increase when steric favor and $\mathrm{H}$-bond acceptor favor groups are substituted on $R_{2}$ position and positive favor group are substituted on $C_{2}, C_{3}$, and $C_{5}$ atom in phenyl ring of $\mathrm{R}_{2}$ position. And the inhubition activities are expected to increase when hy drophobic favor group is substituted on $\mathrm{C}_{1}$ and $\mathrm{C}_{3}$ atom in phenyl ring of $\mathrm{R}_{2}$ position and $\mathrm{Cl}$ aton of $\mathrm{R}_{1}$ position and hydrophilic favor groups are substituted on $C_{4}$ atom in phenyl ring of $R_{2}$ position and the tenminal group of $R_{1}$ position.
\end{abstract}

Key Words: 3D-QSAR COMFA. CoMSIA 2-N-Phenỵlisoindolin-I-one analogues. Protox

\section{Intoduction}

Protox(protoporphyrinogen oxidase: EC 1.3.3.4) inhibitory peroxidizing herbicides ${ }^{1}$ have been reported on herbicidal activity according to the modification of alkoxyanilinosubstituents in the 2-fluoro-4-chloro-5-alkoxyanilino group. ${ }^{2 \cdot 6}$ Especially. the study for the change of heterocyclic group is actively working. The common ones of eight types in hererocyclic group are cyclopentane. tetrahydrophthalimide and bicyclic five-membered heterocyclic analogues. Cyclopentane cyclic groups act as a steric factor to fix the position of alicyclic and benzene ring.

For improving herbicidal activity of protox herbicides. SAR (stnicture-activity relationship) has been studied. ${ }^{3}$ Based on these results. benzoheterocyclic uracil analogues as new protox inhibitors were studied. ${ }^{910}$ Recently. the study of herbicidal activity and biochemistry, and also the physiological studies about $\mathrm{N}$-(4-chloro-2-fluoro-5-propagy loxy) phenyl-3.4.5.6-tetrahỵd drophthalimide analogues have been reported. $^{11,12}$ As part of other trials we reported ${ }^{13.14}$ molecular similarity about not only inhibition activity of 1 -substitutionpheny 1-3,4.5.6-tetrahydrophthalimide and 1 -substituted-phenyl-3.4-dimethylmaleimide analogues but also CoMFA analysis. Especially. it is possible to understand the results of COMFA, COMSIA and HQSAR, ${ }^{15.17}$ about protox inlibition activity of 1-(5-methyl-3-pheny'lisoxazolin-5-yl)-methoxy -2chloro-4-fluorobenzene analogues. Moreover. in the 2-fluoro4-chloro5-alkoxy-anilino group. it was found that the change of alkoxyanilino group on $C_{5}$ atomic position was more effective than the change of $\mathrm{C}$-phenyl group on herbicidal activity. Also protox inhibition activities are more improved when ortho position of C-phenyl group was substituted by the more steric bulky groups.

In this study, the authors have applied CoMFA (comparative molecular field analy sis) ${ }^{18}$ and CoMSIA (comparative mole- cular similarity indices analysis) ${ }^{19}$ as 3D-QSARs (3 dimensional quantitative structure-activity relationships) method to the herbicidal $2-N$-phenylisoindolin-1-one analogues as a new class of potent inhibitors of protox.

\section{Materials and Methods}

Protox Inhibition Activity. To measure protox inhibition activity of substrate compounds synthesized by author's published reference. ${ }^{20}$ the barley and counted chlorophyll contents $^{21.24}$ were selected. Inlubition rate (IN) was calculated by using formula (1).

$$
\mathrm{IN}(\%)=100-\left(\frac{\text { Q'ty chlorophỵll }}{\text { Control }}\right) \times 100
$$

From IN $(\%)$, the $50 \%$ of inhibitory concentration (EC $\mathrm{EC}_{5 \mathrm{c}}$ ) was counted. Then formula (2) was inserted and concentration (ppm) was converted into mole concentration (M). Then, the inhibition activity $\left(\mathrm{pI}_{51}\right)$ was counted from the inversed value of mole concentration with application of $-\log$.

$$
O b s \cdot \mathrm{pI}_{s i}=-\log \left(\frac{\mathrm{EC}_{50}(\mathrm{ppm})}{\mathrm{M} . \mathrm{Wt} . \times 1.000}\right)
$$

Molecular Modeling. All molecular modeling studies, statistical analyses. CoMFA and CoMSIA analyses were performed using SYBYL (Ver. 8.0) program (Tripos Inc.). ${ }^{23}$ We carried out COMFA and CoMSIA analy ses to understand quantitatively on the structure-activity relationships (SARs) with 2-X-phenylisoindolin- 1 -one analogues (Fig. 1). ${ }^{20}$ as the substrate compounds. and Protox inhibition activity (Obs $\mathrm{pI}_{\mathrm{sc}}$ ). Aton partial charge used in the study was applied GasteigerHuckel charges ${ }^{2+35}$ and the most stable conformation of the nolecules was obtained by simulated annealing method. ${ }^{26}$ In 
this study, CoMFA and CoMSIA models were achieved from training set $(n-31)$ in the data set $(n-37)$ compounds and predictions for the models were evaluated from test set $(n=6)$ compounds. Two different alignment rules in the present study were used: atom based tit $(\Lambda \mathrm{F})$ alignment ${ }^{27}$ and field fit (FF) alignment. ${ }^{28} \mathrm{AF}$ alignment was alignment of the potential energy minimized substrate structures and the results of the alignment of the molecules using AF alignment as shown in Figure 2. On the contour maps, the rate of favor and disfavor contribution ( $\%$ ) was $80 \%$ and $20 \%$, respectively.

Calculation of PLS. To conduct CoMFA and CoMSIA model, training set and test set was sel arbitrarily. Cortelationships between 3D-structural feature of aligned compounds on three dimensional spaces and biological activities were calculated by using the PLS (partial least squared) method. ${ }^{29}$ The cross-validated melhod was also used to determine the number of optimal component and $r^{2}$ v. value (or $q^{2}$ ) was represented predictability from the analytical results. The predictive maximum q' value and the number of components from the result containing minimum error were selected as optimum number. Cross-validation used leave-one-out (L.OO) method, ${ }^{3 n}$ which is, excluded compounds from data set by ones. Based on this, correlation coefficient $\left(r^{2}\right.$ ns. $)$ was calculated by the non-cross-validation process (scaling: CoMFA standard. column filtering: $2.0 \mathrm{kcal} / \mathrm{mol}$ ). When correlation coefficient $\left(\mathrm{r}^{2}\right.$ Icr $)$ was more than 0.90 and predictability $\left(\mathrm{r}^{2} \mathrm{cr}\right.$ or $\left.\mathrm{q}^{2}\right)$ value was more than 0.50 , it is possible to estimate the model has predictability. The component number from the result was used for no-validation and 3D-QSAR model. $\Lambda$ lso. PRESS (predictive residual sum of the square of the training set) values were calculated by the sum of square deviation between observed values $\left(O b s . \mathrm{pl}_{\mathrm{s} \sigma}\right)$ of training set and predicted values (Pred.plso).

\section{Results and Discussion}

3D-QSAR Models. Observed protox inhibition activity (Obs.pl $\left.{ }_{50}\right)$ of substrate analogues (Fig. 1) has the highest inhibition aclivily ( ()$_{s}$. $\left.\mathrm{pl}_{50}=6.98\right)$ for compound $29\left(\mathrm{R}_{1}=2\right.$ chloroally and $R_{\underline{2}}=4$-methoxythiophenyl group). On the other hand, it has the lowest inhibition activity (Obs.pl $\mathrm{s}_{50}=$ $4.66)$ for compound $20\left(R_{1}=2\right.$-chloroally and $R_{2}=$ etlyylthio group). According to the change of the substitution group of substrate analogues, CoMFA model and CoMSIA model (Table I) were calculated from AF and FF alignment. Statistical values of 3D-QSAR models were generated according to the combination condition of range of grid $(1.0 \sim$ $3.0 \mathrm{~A}$ ), COMFA field and CoMSIA field as summarized in Table 2. In CoMFA models, CoMFA 1 model $\left(r^{2}{ }^{2}=0.414\right.$ and $\left.r^{2}{ }_{n c v}=0.909\right)$ from AF alignment condition combined standard field, indicator field and $\mathrm{H}$-bond field was more satis-

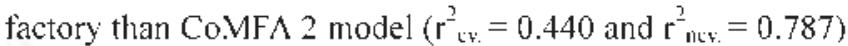
from $\mathrm{F} F$ alignment condition. However, the two models were not appropriate because both models could not come to the standard of predictive level $\left(\mathrm{r}^{2}\right.$ or $\left.\mathrm{q}^{2}>0.5\right)$.

In CoMSI $\Lambda$ models, CoMSl $\Lambda 2$ model $\left(\mathrm{r}^{2}{ }^{2}=0.612\right.$ and $\left.r^{2}{ }_{n v .}=0.973\right)$ from $\mathrm{FF}$ alignment condition was the more appropriate model with higher correlation than CoMSIA 1

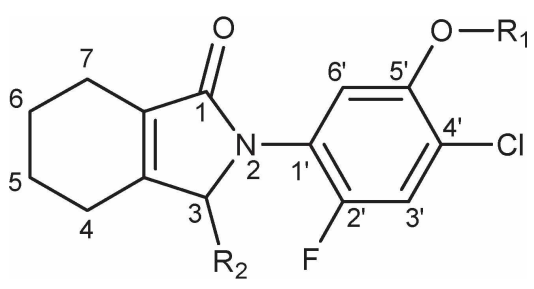

Figure 1. General structure and numbering scheme of 2-, -phenylisoindolin-1-one analogues $\left(R_{1} \cdots R_{2}\right)$.

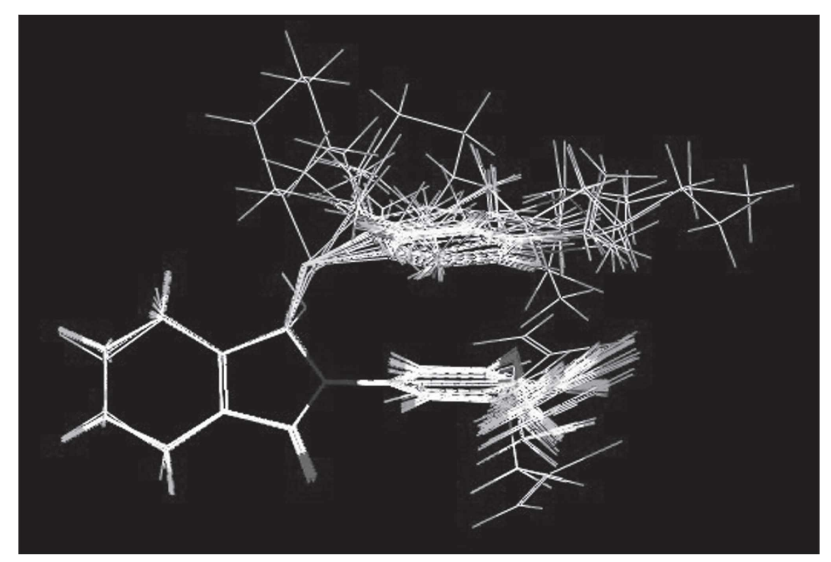

Fïgure 2. Alignment of the potential energy minimized substrate structures according to a least-squares atom based fit.

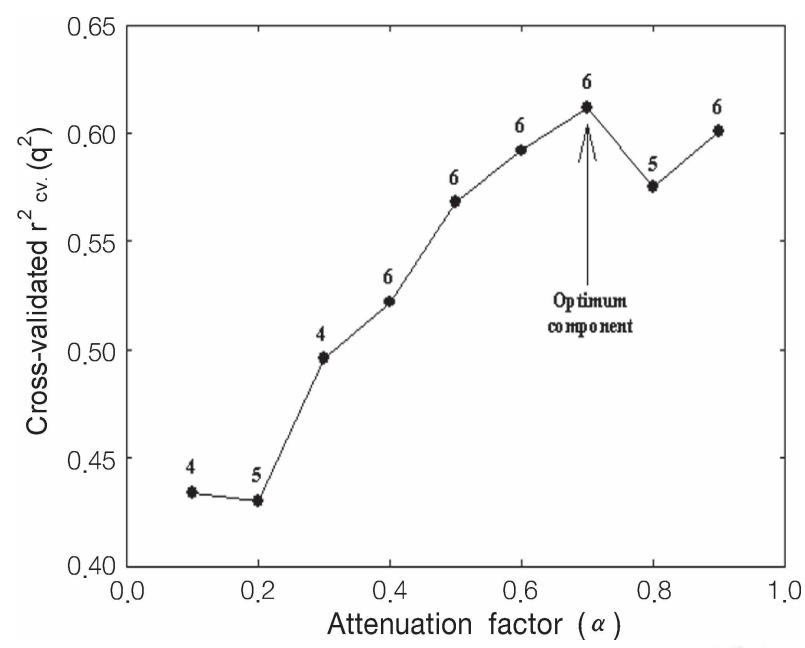

Figure 3. Variation of $\mathrm{q}^{2}$ upon changing the attenuation factor, $\alpha$ used in the distance dependence between probe atoms and atoms in the molecule with CoMSIA models. (The number on top of the point indicates the optimum number of components).

model $\left(r^{2}{ }^{2}=0.618\right.$ and $\left.r^{2}{ }_{r \psi}=0.960\right)$ from $\Lambda F$ alignment condition. Therefore, these two models, CoMSIA 1 and 2 models were delinitely better models than CoMFA 1 and 2 models statistically. Especially, both CoMSIA 1 and 2 models were appropriate models similarly. The optimized CoMSlA 2 model was the optimized model with a high correlationship among four 3D-QSAR models. Observed inhibition activity $\left(O b s . \mathrm{pl}_{50}\right)$ of substrate analogues and predicted inhibition activity $\left(P_{r e d}{ }^{\mathrm{pl}} \mathrm{I}_{S 0}\right)$ by COMSIA 1 and 2 models, and deviation (Dev.) of these two values were summarized in Table 1 . The 
Table 1. Observed inhibition activity (Obs.pI $\mathrm{I}_{0}$ ) against protos and predicted inhibition activity (Pred pI sul $_{1}$ by the optimized CoMSIA models using two alignments

\begin{tabular}{|c|c|c|c|c|c|c|c|}
\hline \multirow{2}{*}{ No. } & \multicolumn{2}{|c|}{ Substituents } & \multirow{2}{*}{ Obs.pIso } & \multicolumn{2}{|c|}{$\mathrm{AF}$} & \multicolumn{2}{|c|}{$\mathrm{FF}^{\circ}$} \\
\hline & $\mathrm{R}_{\mathrm{l}}$ & $\mathrm{R}_{2}$ & & Pred. $^{b}$ & Dev. $^{c}$ & Pred. $^{t}$ & Dev. ${ }^{c}$ \\
\hline 1 & $-\mathrm{CH}_{2} \mathrm{CCH}$ & $\left(\mathrm{CH}_{3}\right) \mathrm{CHS}-$ & 5.07 & 5.04 & 0.03 & 4.98 & 0.09 \\
\hline 2 & $-\mathrm{CH}_{2} \mathrm{CCH}$ & $\left(\mathrm{CH}_{3}\right)_{3} \mathrm{CS}-$ & 5.49 & 5.39 & 0.01 & 5.49 & -0.09 \\
\hline 3 & $-\mathrm{CH}_{2} \mathrm{CCH}$ & $\mathrm{CH}_{2} \mathrm{CHCH}_{2} \mathrm{~S}-$ & 5.74 & 5.73 & 0.01 & 5.71 & 0.03 \\
\hline 4 & $-\mathrm{CH}_{2} \mathrm{CCH}$ & $\mathrm{CH}_{2}\left(\mathrm{CH}_{2}\right) \leq \mathrm{CH}_{2} \mathrm{~S}-$ & 5.95 & 6.02 & -0.07 & 6.08 & -0.13 \\
\hline 5 & $-\mathrm{CH}_{2} \mathrm{CCH}$ & $\mathrm{CH}_{2}\left(\mathrm{CH}_{2}\right)_{5} \mathrm{CH}_{2} \mathrm{~S}-$ & $6.0 \mathrm{l}$ & 6.07 & -0.06 & 6.19 & -0.18 \\
\hline 6 & $-\mathrm{CH}_{2} \mathrm{CCH}$ & $\mathrm{C}_{5} \mathrm{H}_{30} \mathrm{~S}-$ & 5.65 & 5.71 & -0.06 & 5.69 & -0.04 \\
\hline 7 & $-\mathrm{CH}_{2} \mathrm{CCH}$ & Ph.S- & 5.79 & 6.12 & -0.33 & 5.96 & -0.17 \\
\hline 9 & $-\mathrm{CH}_{2} \mathrm{CCH}$ & 2-CHs-Ph.S- & 5.93 & 6.11 & -0.18 & 5.97 & -0.04 \\
\hline 10 & $-\mathrm{CH}_{2} \mathrm{CCH}$ & $3-\mathrm{CH}_{3}-\mathrm{Ph} . \mathrm{S}-$ & 6.69 & 6.93 & -0.24 & 6.94 & -0.25 \\
\hline 11 & $-\mathrm{CH}_{2} \mathrm{CCH}$ & 2-Cl-Ph.S- & 5.80 & 5.79 & 0.01 & 5.79 & 0.01 \\
\hline $1 \hat{3}$ & $-\mathrm{CH}_{2} \mathrm{CCH}$ & 4-Cl-Ph.S- & 6.75 & 6.35 & 0.40 & 6.66 & 0.09 \\
\hline 15 & $-\mathrm{CH}_{2} \mathrm{CCH}$ & 4-r-Ph.S- & 5.44 & 5.46 & -0.02 & 5.38 & 0.06 \\
\hline 16 & $-\mathrm{CH}_{2} \mathrm{CCH}$ & 3-H'-Ph.S- & 6.28 & 6.17 & 0.11 & 6.25 & 0.03 \\
\hline 17 & $-\mathrm{CH}_{2} \mathrm{CCH}$ & 3-CFs-Ph.S- & 5.83 & 5.91 & -0.08 & 5.83 & 0.00 \\
\hline 18 & $-\mathrm{CH}_{2} \mathrm{CCH}$ & 4-CF-Pli.S- & 6.78 & 6.94 & -0.16 & 6.86 & -0.08 \\
\hline 19 & $-\mathrm{CH}_{2} \mathrm{CClCH}_{2}$ & $\mathrm{OH}-$ & 5.70 & 5.73 & -0.03 & 5.60 & 0.10 \\
\hline 20 & $-\mathrm{CH}_{2} \mathrm{CClCH}_{2}$ & $\mathrm{CH}_{3} \mathrm{CH}_{2} \mathrm{~S}-$ & 4.66 & 4.34 & 0.32 & 4.50 & 0.16 \\
\hline 21 & $-\mathrm{CH}_{2} \mathrm{CClCH}=$ & $\left(\mathrm{CH}_{3}\right)_{2} \mathrm{CHS}-$ & 4.91 & 4.73 & 0.18 & 4.91 & 0.00 \\
\hline 23 & $-\mathrm{CH}_{2} \mathrm{CClCH}=$ & $\mathrm{CH}_{2} \mathrm{CHCH}_{2} \mathrm{~S}-$ & 3.96 & 4.44 & -0.48 & 4.18 & -0.22 \\
\hline 24 & $-\mathrm{CH}_{2} \mathrm{CClCH}_{2}$ & $\mathrm{CH}_{3}\left(\mathrm{CH}_{2}\right)_{4} \mathrm{CH}_{2} \mathrm{~S}$ & 6.75 & 6.59 & 0.16 & 6.61 & 0.14 \\
\hline 25 & $-\mathrm{CH}_{2} \mathrm{CClCH}_{2}$ & $\mathrm{CH}_{3}\left(\mathrm{CH}_{2}\right)_{6} \mathrm{CH}_{2} \mathrm{~S}$ & 6.78 & 6.75 & 0.03 & 6.79 & $-0.0 \mathrm{~J}$ \\
\hline 26 & $-\mathrm{CH}_{2} \mathrm{CClCH}_{2}$ & $\mathrm{C}_{6} \mathrm{H}_{10} \mathrm{~S}-$ & 5.78 & 5.96 & -0.18 & 5.81 & -0.03 \\
\hline 27 & $-\mathrm{CH}_{2} \mathrm{CClCH}_{2}$ & 2-CH $\mathrm{CH}_{2} \mathrm{O}-\mathrm{Ph} . \mathrm{S}-$ & 6.75 & 6.70 & 0.05 & 6.70 & 0.05 \\
\hline 29 & $-\mathrm{CH}_{2} \mathrm{CClCH}_{2}$ & $4-\mathrm{CH}_{2} \mathrm{O}-\mathrm{Ph}$.S- & 6.98 & 6.92 & 0.06 & 6.91 & 0.07 \\
\hline 30 & $-\mathrm{CH}_{2} \mathrm{CClCH}_{2}$ & 2-CH $3-\mathrm{Ph} . \mathrm{S}-$ & 6.07 & 6.12 & -0.05 & 5.89 & 0.18 \\
\hline 31 & $-\mathrm{CH}_{2} \mathrm{CClCH}_{2}$ & 3-CHs-Ph.S- & 6.88 & 6.94 & -0.06 & 6.83 & 0.05 \\
\hline 32 & $-\mathrm{CH}_{2} \mathrm{CClCH}_{2}$ & 2-Cl-Ph.S- & 6.68 & 6.43 & 0.25 & $6.6 \mathrm{l}$ & 0.07 \\
\hline 33 & $-\mathrm{CH}_{2} \mathrm{CClCH}_{2}$ & 3-Cl-Ph.S- & 6.21 & 6.00 & 0.21 & 605 & 0.16 \\
\hline 34 & $-\mathrm{CH}_{2} \mathrm{CClCH}_{2}$ & 4-Cl-Ph.S- & 6.74 & 6.40 & 0.34 & 6.60 & 0.14 \\
\hline 35 & $-\mathrm{CH}_{2} \mathrm{CClCH}_{2}$ & 2-r-Ph.S- & 6.74 & 6.73 & 0.01 & 6.78 & -0.04 \\
\hline 36 & $-\mathrm{CH}_{2} \mathrm{CClCH}=$ & 3-t'-Ph.S- & 5.91 & 6.18 & -0.27 & 6.17 & -0.26 \\
\hline
\end{tabular}

Notes: AF: atom based fit: FF: field fit: "optimized model. predicted value by the CoMSIA 1 \& 2 model: "difference between observed (Obs.plin) values and predicted $\left(\right.$ Pred.pI $\left._{\mathrm{su}}\right)$ values.

Table 2. Summary of statistical parameters of 3D-QSAR models with two alignments

\begin{tabular}{|c|c|c|c|c|c|c|c|}
\hline \multirow{2}{*}{ Model No. } & \multirow{2}{*}{ Alignments } & \multicolumn{6}{|c|}{ PLS Analyses } \\
\hline & & Grid $(\AA)$ & $\mathrm{NC}^{a}$ & $\mathrm{r}^{2} \mathrm{CH}^{b}$ & $\mathrm{r}_{\mathrm{mW}}^{2} \mathrm{c}^{6}$ & $\mathrm{SE}_{\mathrm{tiv}}{ }^{d}$ & $\mathrm{~F}$ \\
\hline CoMFA 1 & $\mathrm{AF}$ & 1.0 & 2 & 0.414 & 0.909 & 0.246 & 39.746 \\
\hline COMHA 2 & $\mathrm{FF}$ & 1.5 & 3 & 0.440 & 0.787 & 0.353 & 33.314 \\
\hline CoMSIA 1 & $\mathrm{AF}(\alpha=0.4)$ & 1.0 & 6 & 0.618 & 0.960 & 0.163 & 95.247 \\
\hline $\operatorname{CoMSIA} 2^{\circ}$ & $\mathrm{FF}(\alpha=0.7)$ & 1.0 & 6 & 0.612 & 0.973 & 0.135 & 141.704 \\
\hline
\end{tabular}

Notes: F: fraction of explained versus unexplained variance; attenuation factor: $\alpha$ : "tumber of components: "cross-validated $r^{2}$ " "non-cross- validated r": $d_{\text {standard error estimate. "optimized model. }}$

Table 3. Summary of field contribution and PLS results of 3D-QSAR model

\begin{tabular}{|c|c|c|c|c|c|c|c|c|}
\hline \multirow{2}{*}{ Model No. } & \multicolumn{4}{|c|}{ Field contribution (\%) } & \multicolumn{2}{|c|}{ Training set } & \multicolumn{2}{|c|}{ Test set } \\
\hline & $\mathrm{S}$ & $\mathrm{Hy}$ & $E$ & $\mathrm{HA}$ & PRESS & Ave. & PRESS & Ave. \\
\hline CoMFA l & 76.9 & 6.60 & 16.5 & - & 5.962 & 0.331 & 3.547 & 0.737 \\
\hline CoMFA 2 & 62.6 & 24.8 & 12.6 & - & 3.327 & 0.243 & 3.307 & 0.697 \\
\hline COMSIA 1 & 24.5 & 27.4 & 25.8 & 22.3 & 1.149 & 0.145 & 4.469 & 0.707 \\
\hline $\operatorname{CoMSIA} 2^{\prime \prime}$ & 24.6 & 23.4 & 31.0 & 21.0 & 0.446 & 0.096 & 3.065 & 0.543 \\
\hline
\end{tabular}

Notes: S: steric field: E: electrostatic field: Hy: hydrophobic tield: HA: H-bond acceptor field: "optimized model. 
Table 4. Observed protox inhibition activity (Obs.pI sa) and predicted protox inhibition activity (Pred.pI s. by the optimized CoMSI A models for the test set

\begin{tabular}{|c|c|c|c|c|c|c|c|}
\hline \multirow{2}{*}{ No. } & \multicolumn{2}{|c|}{ Substitucnts } & \multirow{2}{*}{$O b s .\left.p\right|_{5<1}$} & \multicolumn{2}{|c|}{$\mathrm{AF}$} & \multicolumn{2}{|c|}{$\mathrm{FF}$} \\
\hline & $R_{1}$ & $\mathrm{R}_{2}$ & & Pred." & Dev. & Pred." & Dev." \\
\hline 8 & -CIleCll & 2-CH3OPh.S- & 6.27 & 5.48 & 0.79 & 5.85 & 0.42 \\
\hline 12 & - & 3-Cl-Ph,S- & 5.70 & 5.78 & -0.08 & 5.66 & 0.04 \\
\hline 14 & $-\mathrm{CH}_{2} \mathrm{CCH}$ & 2-F-I'h.S- & 5.05 & 5.49 & -0.44 & 5.74 & -0.69 \\
\hline 22 & $-\mathrm{CH}_{2} \mathrm{CClCH}_{2}$ & $\left(\mathrm{CH}_{3}\right)_{3} \mathrm{CS}-$ & 6.06 & 4.60 & 1.46 & 4.66 & 1.40 \\
\hline 28 & $-\mathrm{CH}_{2} \mathrm{CClCl}_{2}$ & 3-CHBO-Ph.S- & 5.76 & 6.96 & -1.20 & 6.43 & -0.56 \\
\hline 37 & $-\mathrm{CH}_{2} \mathrm{C} \times 1 \mathrm{CH}_{2}$ & 3-CFPl.S- & 5.87 & 6.14 & -0.27 & 5.91 & -0.04 \\
\hline
\end{tabular}

"Ihe values were calculated according to the optimized CoMSIA I and 2 models in Table 3: "difference between observes activity (Obs.plin) and predictsed activity (Pred.pI su $\left._{1}\right)$

optimized CoMSIA 2 model was combined with steric lield. hydrophobic field. electrostatic field and l[-bond accept lield. From attenuation factor $(\alpha-0.7)$ related to the distance between probe atom and atoms in substrate molecule. cross-validated $\mathrm{q}^{2}$ (or $\mathrm{r}^{2}{ }_{\mathrm{s}}=0.62$ ) value ( $\Gamma$ ig. 3) was the highest and most optimal component number was 6 in grid 1.0 ( A).

The contribution ratio $(\%)$ of distinction ficlds in 3[)QSAR models, average residual ( $\Lambda$ ve.) and redictive residual sum of squares (l'RESS) of training set ( lable l) and test set compounds (Table 4) were summarized in Table 3. The Ave, and PRESS values of training set and test set with the optimized CoMSiA 2 model were the lowest. From the results. we could understand that CoMSl/ 2 model is the most optimized model in all models. The contribution ratio (\%) of electrostatic field, steric field, hydrophobicity lield and ] [-bond acceptor field in CoMS]A 2 model was 31.0, 24.6. 23.4 and $21.0 \%$ respectively. Flectrostatic ficld of substrate molecule was greatly contributed to protox inhibition activity. Based on these results. the proportional relationships between observed activities (Obs.p $I_{50}$ ) related to protox inhibition activity and calculated activities (Pred.pI $I_{0}$ ) by the optimized CoMSIA 2 model were shown in Figure 4. It was expected the statistically appropriate predictibility from this linear

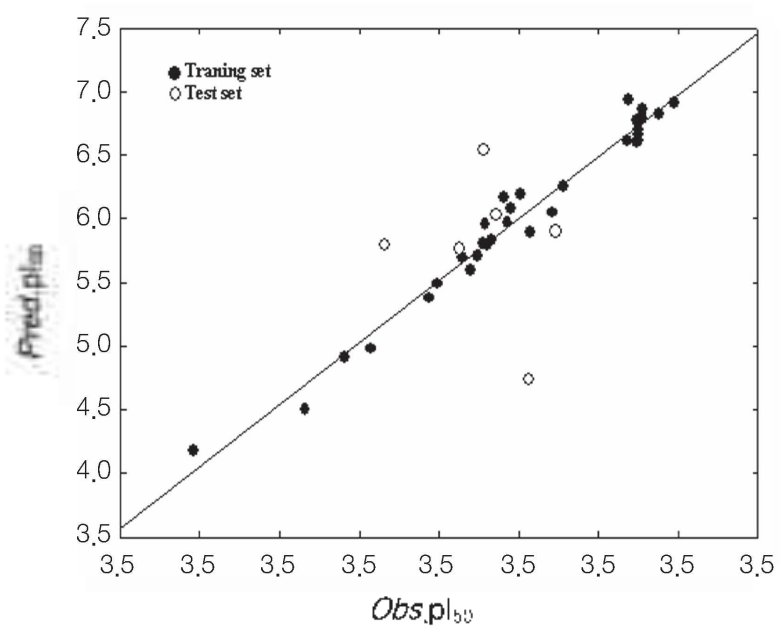

Figure 4. Relationships between obstrved protox inhibition activitics

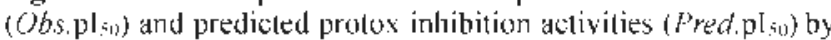
the optimized CoMSIA model (rield fit) (For training set: Pred.pl $\mathrm{s}_{513}-0.9730 \mathrm{bs} . \mathrm{pl} \mathrm{I}_{\mathrm{s}}-0.163 \mathrm{n}-31 \mathrm{~s}-0.122, \mathrm{~F}-1014.78$. $\left.r^{2}=0.972 \& \mathrm{q}^{2}=0.970\right)$. equation (Pred.p $\left[_{\mathrm{si}}=0.9730 \mathrm{lbs}, \mathrm{p}\right]_{\mathrm{s} 0}+0.163, \mathrm{n}=3 \mathrm{l}, \mathrm{s}=0.122$. $\mathrm{F}=1014.78 \cdot \mathrm{r}^{2}=0.972$ and $\mathrm{q}^{2}=0.970$ ).

Analyses of CoMSIA Contour Maps. The contour maps of the optimized CoMSIA 2 model were represented in Figure 5 and Figure 6. And the most aclive compound $29\left(R_{1}=2\right.$ chloroally and $R_{2}=4$-methoxythiophenyl) is shown in capped sticks. The contour maps in the sterie field and the H-bond donor field were represented in Figure 5. The yellow polyhedral regions appeared around $R_{2}$-substituent and its inhjbition activity was decreased by bulky substituent sterically. Also. in $\mathrm{S}$-atom region of $\mathrm{R}_{2}$-substituents (RS). inhibition

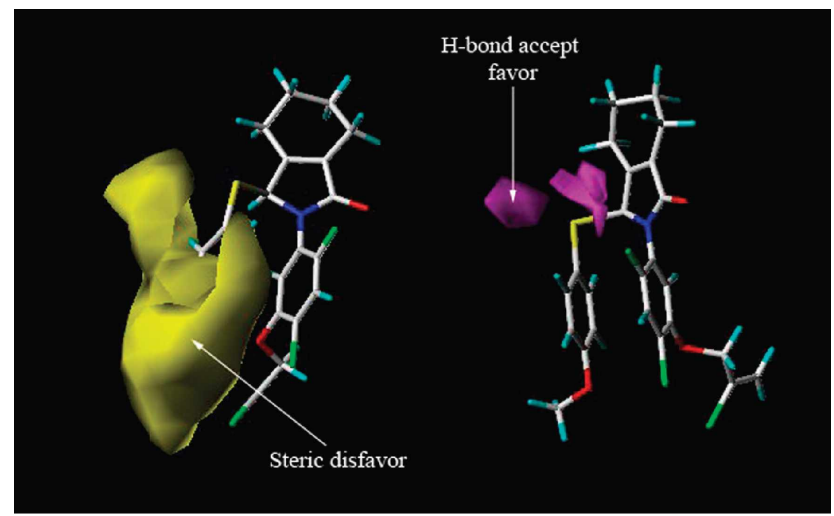

Figure 5. The contour maps of the CoMSIA 2 model for steric lield activity (lelt side) and $\mathrm{H}$ l-bond accept field (right side) (stdev* coeff). The most active compound (29) is shown in capped sticks.

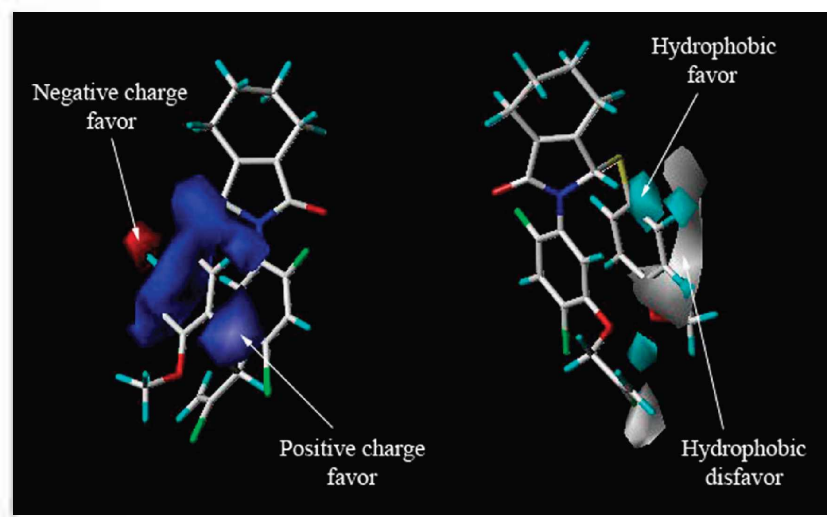

Figure 6. The contour maps of the CoMS1A 2 model for electrostatic field (left side) and hydrophobic field (right side) (stdev* coeff). The most active compound (29) is shown in capped sticks. 
activity was implied increase by the substituent (purple color) favored $\mathrm{H}$-bond acceptor field. The contour maps in the electrostatic field and the hydrophobic field were represented in Figure 6. According to the results of the contour maps in the electrostatic field the blue poly hedra favored positive charge were strongly expressed in two positions: where in combination of $R_{2}$-substituent and its template. where in $C_{2}+C_{3}$ and $\mathrm{C}$ : carbon atoms of phenyl ring. The inhibition activity was presumed increase by the positive charge substituent in the blue polyhedra and by negative charge substituent (red color poly hedra) in $C_{6}$ carbon atom. According to the results of the contour maps in the hydrophobic field on the right side. the protox inhibition activity was predicted increase by not only the hydrophobic substituent (silver polyhedral region) in $\mathrm{C}_{1}$ atom of S-phenyl ring and $\mathrm{C}_{5}$ of carbon atom but also the hydrophilic substituent (cyan polyhedral region) in $\mathrm{C}_{4}$ carbon atom of S-phenyl ring. From the analyses results of these optimized CoMSIA 2 model. the structural distinctions that contribute to the herbicidal activity with inhibition of protox were obtained.

\section{Conclusion}

The CoMSIA 2 model is the most optimized $\left(\mathrm{r}_{\mathrm{cr}}^{-}=0.612 \&\right.$ $\mathrm{r}_{\text {nac }}^{2}=0.973$ ) model among four 3D-QSAR models from two alignment conditions ( $\mathrm{AF}$ and $\mathrm{FF}$ ) to explain the protox inhibition activity of herbicidal substrate molecules. According to the distinction field. the protox inhibition activities depend on the electrostatic field ( $31.0 \%$ ). From the contour maps. when steric factor is small in $\mathrm{R}_{2}$-substituent position. inhibition activity is increased. The substituent preferred to the positive charge at $\mathrm{C}_{3}, \mathrm{C}_{3}$ and $\mathrm{C}_{5}$ carbon atom in phenyl ring, and the substituent preferred to the negative charge at $\mathrm{C}_{6}$ carbon atom making inhibition activity increase. Also the protox inhibition activity was predicted increase by not only the hydrophobic substituent at $C_{1}$ and $C_{3}$ carbon atom of $R_{2}$-substituent in $S$-phenyl ring but also the hydrophilic substituent at $\mathrm{C}_{\mathrm{l}}$ atom position of $R_{3}$-substituent. $C_{4}$ carbon atom and in the end of $\mathrm{R}_{1}$-substituent.

Acknowledgments. This work was supported by a grant (No. R11-2002-100-00503) from Engineering Research Center $(E R C)$ Program of the Korea Science and Engineering Foundation (KOSEF).

\section{References}

1. Boger, P.; Wakabayashi, K. In Peroxidizing Herbicides: SpringerVerlag: Berline, Heidelberg, Germany, 1999.

2. Fujita, T. In Agrochentical Discovern, Insect, Weed, and Fumgal Control: Similarities in Bioanalogous Structural Transfor- mation Pattenn, ACS Symposium Series: Baker, D). R.; Umetsu, N. K., Eds:; American Chemical Society: Washington DC. 2002: Ch. 15, No. 774 .

3. Hiraki, M:: Onki, S.; Sato, Y; Tablonkai, I.; Boger, P: Wakabayashi, K. Pesticide Biochemistry and Physiology 2001, 70,159

4. Ishida, S.: Miller-Sulger, R.: Kohno, H.: Boger, P.: Wakabayashi, K. J. Pestic. Sci. 2000, 25, 18

5. Iida, T; Uchida, A.; Uraguchi, R.; Sato, Y.; Boger, H.; Wakabayashi, K. J. Pestic. Sci. 1997, 22, 303

6. Ishida, S.: Hirai, K.; Kohno, H.; Sato, Y: Kubo, H.; Boger, H.; Wakabayashi, K. J. Pestic. Sci. 1997, 22, 299

7. Pallett, K. E. Proceeding of Bringhton Crop Protection ConferenceWeeds; 1997; p 575.

8. Theodoridis, G. Pestic. Sci. 1997, 50, 283

9. Theodoridis, G.: Bahr, I. T.: Hotzman, F. W.; Sehgel, S.: Suares, D. P. Crop Prot $\mathbf{2 0 0 0 , 1 9 , 5 3 3}$

10. Hiraki, M.: Ohki, S.; Sato, Y.: Jablonkai, I.: Boger, P.: Wakábayashi, K. Pesticide Biochemistry and Phusiology 2001, 70, 159.

11. Watanabe, N.; Takayama, S.: Yoshida, S.: Isogai, A.; Che, F. S Biosci. Biotechnol Biochem. 2002, 66, 1799.

12. Dayan, F. E.: Duke, S. O.: Reddy, K. N.; Hamper, B. C.: Leschinsky, K. L. J. Agric. Food Chem. 1997, t5, 967

13. Sung, N. D.; Ock, H. S.; Chung, H. J.; Song, J. H.; Lee, Y. G. Kon: J. Pest. Sci. 2003, 7,75.

14. Sung, N. D.; Ock, H. S.; Chung, H. J.; Song, J. H. Kor J. Pest. Sci. $2003,7,100$.

15. Sung, N. D.; Song, T. H.; Yang, S. Y.; Park, K. Y. Kor J. Pest. Sci. 2004, 8, 151

16. Surg, N. D.; Song. T. H.; Park, K. Y. J. Kor Soc. Appl Biol. Chem. 2004, 47,351.

17. Sung, N. D.: Song. T. H.: Park, K. Y. J. Kor Soc. Appl. Biol. Chem. 2004, 47,4l4.

18. Cramer, R. D., III; Patterson, D. E.; Bunce, J. E. J. Am. Chem. Soc. $1988,110,5959$.

19. Klebe, G.; Abraham, U.; Mietzner, T. J. Med. Chem. 1994, 37. 4130 .

20. Cho, Y. G.; Soung. M. G.: Sung. N. D. 2007 Intenational Simposim and Annal Meeting of the $\mathrm{KS} A B C$, Gyeongu, Korea, 2007.

21. Tohan, B. Photochem and Photobiol. 1963, 2,241

22. Hiscon, J. D.; Israelstan. G. F. Can. J. Bot. 1978, 57,1332

23. Tripos, Sybyl. Holecular Hodeling and OSAR Software on CD-Rom (Ver. 7.3); Triopos Associates, Inc.: Suite 303, St. Louis, MO.

24. Purcell, W. P.; Singer, T. A. J. Chent. Eng. Data 1967, 122, 235.

25. Gasteiger, J.: Marsili, M. Tewahedron 1980, 36, 3219 .

26. Кеп, K. Biopins. J. 1964, 67, 1501.

27. Marshall, G. R.; Barry, C. D.: Bosshard. H. E.: Dammkoehler. R.

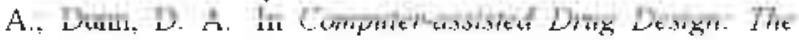
Conformational Parameter in Dng Design; Active Analog Approach: Olsen, E. C.: Christottersen, R. E., Eds:; American Chemical Society: Washington, D.C., 1979; p 205.

28. Clark, M.: Cramer III, R. D.: Iones, D. M.; Patterson, D. E.; Simeroth, P. E. Tetrahted won Contput Methodol 1990, 3, 47.

29. Stahle, L.; Wold, S. Progr. Hed. Chem. 1988, 25, 292.

30. Cramer, R. D.; Bunce, I. D.; Patterson, D. E. Oltont Struct Act. Retot. 1988, 7, 18. 